
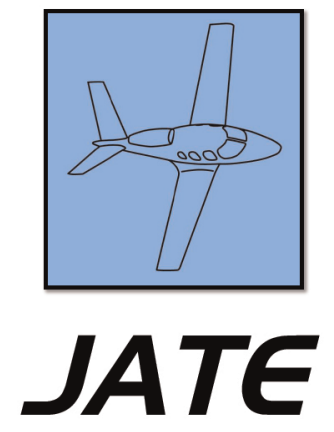

Journal of Aviation Technology and Engineering 2:2 (2013) 13-23

\title{
The 2012 Pilot Source Study (Phase III): Response to the Pilot Certification and Qualification Requirements for Air Carrier Operations
}

\author{
Guy M. Smith and Derek Herchko \\ Embry-Riddle Aeronautical University at Daytona Beach \\ Elizabeth Bjerke \\ University of North Dakota
}

Mary Niemczyk and Robert Nullmeyer

Arizona State University

Julie Paasch

Westminster College

David A. NewMyer

Southern Illinois University

\begin{abstract}
The 2012 Pilot Source Study (Phase III) was a continuation of the 2010 Pilot Source Study (Smith, Bjerke, NewMyer, Niemczyk \& Hamilton, 2010), using the same research design with a new data set containing no duplicate records. University faculty and students assisted seven regional airlines to enter data on 4,024 pilots hired between 2005 and 2011. New-hire pilots' college and piloting backgrounds defined their input (Source) variables. Training and first year operations data defined the output (Success) variables. Identifying information for pilots and participating airlines was removed from the data sets, and records were combined into a single data set for independent analysis by five researchers. Results were verified by two independent researchers from the University of Central Florida (a non-affiliated university). Results showed considerable consistency between the 2010 Pilot Source Study and the 2012 Pilot Source Study regarding initial pilot training at a regional air carrier. The study found that pilots entering the industry with an aviation-specific college degree, particularly a degree from an AABI-accredited flight program, performed better in initial training than those with no degree or a non-aviation degree. The results also indicated that a pilot's background, such as having a CFI certificate and obtaining advanced training from a collegiate aviation program, is an indicator of success in training. One important result was that commercial pilots had more completions than pilots with an ATP certificate. On the other hand, total flight hours produced inconclusive results.
\end{abstract}

Keywords: AABI, air carrier, aviation degree, CFI, first officer, flight hours, flight instructor, Part 141, Part 61, pilot certification, pilot source study, pilot training, regional airline 


\begin{abstract}
About the Authors
Dr. Guy M. Smith received a doctorate in Adult and Higher Education in 1994 from Montana State University. He is an associate professor and the department chair of Applied Aviation Sciences at Embry-Riddle Aeronautical University in Daytona Beach, FL. His current research includes aviation human factors, aviation psychology, crew resource management, line-oriented flight training, and airline pilot selection and training. He is co-editor of "Facilitation and Debriefing in Aviation Training and Operations." Dr. Smith is a Certificated Flight Instructor. He was president of the University Aviation Association (UAA) in 2006-2007. Correspondence concerning this article should be sent to ypsilon@earthlink.net.
\end{abstract}

Derek Herchko received a bachelor's degree in Aeronautical Science and a master of science in Aeronautics (Operations \& Safety) from Embry-Riddle Aeronautical University's Daytona Beach campus. He gathered data and conducted research for the 2010 Pilot Source Study, which he subsequently used as part of his Master's thesis. He is currently the Director of Internal Evaluations for a Part 121 air carrier.

Dr. Elizabeth Bjerke is an associate professor of Aviation at the University of North Dakota. She also serves as the associate chair for the Department of Aviation. Elizabeth has a PhD in Educational Leadership, and focuses her research efforts on aviation education, specifically student persistence and success. Elizabeth also holds a Commercial Pilot Certificate with Airplane Single-Engine Land and Sea, Multi-Engine Land ratings, as well as a Flight Instructor Certificate with Airplane Single and Multi-Engine, Instrument Airplane ratings.

Dr. Mary Niemczyk is an associate professor and chair of the Aviation Programs at Arizona State University (ASU). She earned her PhD in Learning \& Instructional Technology at ASU. She was a financial analyst at a major US carrier and co-founder of an aviation human performance company. Dr. Niemczyk's research interests center on improving instructional and learning strategies to enhance performance in complex, ill-defined environments, such as aviation. Her work also focuses on determining the best attributes, knowledge and skills that can lead to successful performance in aviation training and job performance. She is an FAA certificated pilot.

Robert Nullmeyer is a faculty associate with Arizona State University in the College of Technology and Innovation. He teaches human factors in aviation and crew resource management/line-oriented flight training.

Julie Paasch received her flight training and a bachelor of science in

Aeronautics at the University of North Dakota. She also completed a master of education degree from Westminster College with a certificate in Adult Learning. She is the director of Flight Education and Chief Flight Instructor at Westminster College. Julie is a three-time Master CFI. Her research interests

Dr. David A. NewMyer is a professor and chair of Southern Illinois University Carbondale's (SIUC) Department of Aviation Management and Flight. He was president of the University Aviation Association, "the voice of collegiate aviation," in 2009-2010. Dr. NewMyer received the organization's Sorenson Award for "Outstanding Achievement of Excellence in Aviation Research/Scholarship" and the William A. Wheatley Award for Excellence in Post-Secondary Aviation Education. He earned a doctorate in education administration from SIUC in 1987.

The study was partially funded by FAA contract number DTFA02-03-D-00037, awarded to Dr. Guy M. Smith, principal investigator for the 2012 Pilot Source Study, Phase III.

\section{Background}

In 2010, the United States (US) Congress directed the Federal Aviation Administration (FAA) to conduct a rulemaking proceeding to amend 14 CFR Part 61 to modify the requirements for issuing an Air Transport Pilot (ATP) certificate (Airline Safety and Federal Aviation Administration Extension Act of 2010). In February 2012, the FAA (2012) responded by issuing a Notice of Proposed Rulemaking (NPRM) that would create new certification requirements for pilots in air carrier operations. The proposal would require a first officer in 14 C.F.R. Part 121 operations to hold an ATP certificate and a type rating for the aircraft to be flown. In the NPRM, the FAA proposed allowing pilots with an aviation degree or military pilot experience and with fewer than 1,500 total flight hours to obtain an ATP certificate with restricted privileges. In order to verify the 2010 Pilot Source Study (Smith, Bjerke, NewMyer, Niemczyk, \& Hamilton, 2010), this study used the same research design as the 2010 Pilot Source Study, but utilized an entirely different dataset. Seven regional airlines participated in the 2012 Pilot Source Study: ExpressJet Airlines, SkyWest Airlines, Air Wisconsin Airlines, Atlantic Southeast Airlines, Shuttle America, Chautauqua Airlines, and Republic Airways. The only airline that participated in both studies was Atlantic Southeast Airlines (ASA); however, no duplicate records from ASA were in either data set.

\section{Design and Procedures}

To facilitate combining individual airline data into a composite database, each participating airline was contacted to ensure that comparable data was collected. Trained faculty and students visited the airlines to assist in data collection at each airline's human resources, training, and operations offices. Data leaving the airlines were de-identified, assigned a study identification number, and transmitted to the principal investigator by an online survey tool (SurveyMonkey, 2012). De-identified data were then aggregated with those from other airlines and analyzed independently by five principal researchers and two assistants.

The study was partially funded by FAA contract number DTFA02-03-D-00037 in which the Statement of Work stated:

Continuing with the protocol of Pilot Source Study, Phases I and II, the data will be independently analyzed by five experienced researchers. Because these researchers are all members of universities that have Aviation Accreditation Board International (AABI) accredited flight programs, an external evaluator, not employed by 
AABI-accredited flight programs, will analyze the data. (para. 4)

Consequently, under a Consulting Services Agreement (Smith, 2011) dated August 15, 2011, part of the FAA contract paid for an independent analysis of the dataset by two researchers from the Department of Applied Experimental and Human Factors at the University of Central Florida (UCF). These researchers were not connected to the Aviation Accreditation Board International (AABI), and UCF does not have a flight training program. The report from the independent researchers supports the authors' results and conclusions contained herein.

\section{Population}

The target population consisted of regional airline pilots who had entered initial pilot training between the years of 2005 and 2011. The sample consisted of a convenience sampling of pilots from regional airlines that agreed to participate in the 2012 Pilot Source Study, Phase III. Individual pilots did not supply any data for this study; all data were obtained from airline historical records that were retrieved from the training, operations, and human resources departments by the data collectors. The dataset contained 4,024 records that were collected from the seven airlines and aggregated into a single de-identified database for analysis.

\section{Research Questions}

1) Was there a difference in the number of Extra Training Events for pilots in Part 121 regional airline training, based on College and Piloting Backgrounds?

2) Was there a difference in the number of Training Completions for pilots in Part 121 regional airline training, based on College and Piloting Backgrounds?

3) Was there a difference in the number of unsatisfactory grades in First Year Line Observations for pilots in Part 121 regional airlines, based on College and Piloting Backgrounds?

4) Was there a difference in the number of unsatisfactory grades in First Year Recurrent Training for pilots in Part 121 regional airlines, based on College and Piloting Backgrounds?

\section{Literature Review}

The air transportation industry in the United States relies on a combination of services from both mainline and regional carriers. Throughout the past several years, the role of the regional airline has been rapidly expanding. For example, in 2010, regional carriers served over 670 airports and transported approximately 163 million passengers, accounting for roughly one out of four airline passengers in the US. These statistics have been trending upwards for the past 20 years and are forecasted to continue in this manner (Regional Airline Association [RAA], 2012).

Because of their growth, along with their quest to maintain low operating costs, regional carriers are compelled to utilize practical business practices. Unlike many mainline carriers, regional airline operators often recruit less experienced pilots. In recent years, airlines have selected applicants from a pilot pool where the level of experience is not as extensive as that of pilots from previous generations (Airline Pilots Association [ALPA], 2009). Combined with the diminishing availability of military pilots, the insufficient pilot pool has forced some regional carriers to hire pilots with less flight experience. While every airline develops their unique preferred characteristics, attributes, and expertise of pilot hires; some regional airlines have felt a pressure to trim down their requirements due the lack of ideal pilot candidates (Fanjoy, Young, \& Suckow, 2006).

Further complicating the issue of lowered hiring standards is the cyclical nature of airline hiring. Airline expansion and hiring is largely affected by economic conditions, and regional airlines especially must adjust their hiring minima to keep up with demand when the economy is doing well. This was the case in 2007, when regional airlines were forced to lower their hiring minima because of an increased demand for air travel. This practice resulted in hiring less-experienced pilots, which some people believed could compromise safety (Fullingim, 2007).

Even though there have been tremendous advances in aircraft technologies, pilots are still responsible for the safety of flight operations. The flight environment is dynamic and can involve unexpected situations such as aircraft system malfunctions, severe weather, irate passengers, or other unanticipated events. There has been concern that low-time pilots may not have the knowledge and skills to appropriately manage these situations. Investigations of recent accidents seem to indicate that safety margins and pilot training programs may not have adequately prepared lowtime pilots to address emergency situations (ALPA, 2009).

Safety is the focal point of the air transportation industry as well as the Department of Transportation (DOT). In order to ensure a safe transportation system, comprehensive standards, rules and regulations have been established for all aspects of operations within the national airspace system. Though the safety record of the industry has been exceptional throughout its history, several recent events involving regional carriers have drawn a great deal of attention from the flying public and government officials concerning practices used by some regional airlines. Accidents involving Pinnacle Airlines Flight 3701 (National Transportation Safety Board [NTSB], 2007a), Comair Flight 5191 (NTSB, 2007b), and specifically Colgan Air Flight 3407 (NTSB, 2010), brought to the forefront possible issues regarding pilot training and qualifications. These accidents have invoked strong reactions from the 
DOT, FAA, and Congress with imperatives to investigate and modify current regulations (DOT 2010).

Following the Colgan Air accident in Buffalo, New York on February 12, 2009, Congress and the traveling public called for increased requirements for pilots who fly for regional airlines in the United States, especially first officers (Lopez, 2010). To answer these concerns, Congress enacted the Airline Safety and Federal Aviation Administration Extension Act of 2010 (PL 111-216), which specifically directed the FAA to conduct a rulemaking proceeding to modify the requirements for pilots operating in Part 121 air carrier operations.

Prior to the issuance of PL 111-216, the FAA issued an Advance Notice of Proposed Rulemaking (ANPRM), titled New Pilot Certification Requirements for Air Carrier Operations, to gather information on the adequacy of eligibility, training, and qualification requirements for commercial pilot certification (FAA, 2010). The FAA had a limited window of time to collect public comments about the proposed rulemaking, which included adding credits for gaining experience above normal flight training and for attending a college or university with an accredited aviation program (FAA, 2010). The ANPRM focused on the need to improve pilot performance and professionalism standards, particularly in regards to training for commercial pilots involved in Part 121 operations. Through a series of questions, the FAA sought input and recommendations on five concept areas. One question in particular gained the attention of educators, regional airlines and two international aviation organizations: Aviation Accreditation Board International (AABI) and the University Aviation Association (UAA). Question 2A asked, "Are aviation/ pilot graduates from accredited aviation university degree programs likely to have a more solid academic knowledge base than other pilots hired for air carrier operations? Why or why not?" (FAA, 2010, p. 7). To answer this question more thoroughly; educators, regional airlines, AABI, and UAA authorized a study to determine the performance outcomes of new pilot training for first officers in Part 121 operations (Smith et al., 2010).

The 2010 Pilot Source Study (Smith et al., 2010), was conducted by researchers from five independent universities: Arizona State University, Auburn University, Embry-Riddle Aeronautical University, Southern Illinois University, and the University of North Dakota. It included participation by six regional airlines: American Eagle Airlines, Atlantic Southeast Airlines, Cape Air, Horizon Air, Mesa Airlines, and Trans States Airlines, whose participation consisted of providing access to pilot records typically kept in human resources, pilot training, or flight operations. The research questions in the 2010 Pilot Source Study were:

1. What were the characteristics of pilots who were hired by the US regional airlines between 2005-2009?
2. How did these characteristics relate to their success in regional airline training programs? (Smith et al., 2010, p.76).

The 2010 Pilot Source Study produced five significant findings:

- Pilots who were certificated flight instructors (CFI) had fewer extra training events and had comparatively fewer non-completions than pilots who were not flight instructors;

- Pilots who earned their college degree in an AABIAccredited Flight Program had fewer extra training events and fewer non- completions in initial training;

- Pilots who received their advanced training in college had fewer extra training events and comparatively fewer non-completions in regional airline training programs;

- Pilots who had an aviation degree experienced fewer extra training events and comparatively fewer noncompletions in initial training; and

- Pilots with 501 to 1,000 total flight hours had comparatively fewer extra training events than pilots in any other total flight hour category, and these pilots also had comparatively fewer non-completions.

These results from the 2010 Pilot Source Study are particularly meaningful because the Airline Safety and Federal Aviation Administration Extension Act of 2010 placed importance on Total Flight Hours and required a minimum of 1,500 hours before a pilot can "function effectively in an air carrier operational environment." In contrast, the 2010 Pilot Source Study showed that having more than 1,500 hours did not improve performance. In fact, the study's order of performance was: Group 1 (501-1,000 hours), Group 2 (178500 hours), Group 3 (1,001-1,500 hours) and Group 4 (greater than 1,500 hours) (Smith et al., 2010).

The 2010 Pilot Source Study yielded such interesting results that sponsors from the industry, universities, and government requested that the study be expanded in order to assess more accurately the characteristics of new-hire pilots and the relationships of these characteristics to their success in initial training. The current study, the 2012 Pilot Source Study, acquired data from a larger population of regional airline pilots, focusing on variables collected in the 2010 Pilot Source Study, and compared the results of the two studies.

\section{Results}

\section{Descriptive Statistics: College Backgrounds}

All of the airlines in the 2012 Pilot Source Study, Phase III had some information about their pilots' academic background. The data collection instrument collected: (a) the name of the college or university, (b) the type of college degree (BS, BA, AS, or AA), and (c) the name of the college degree. In the data set, 701 pilots $(17 \%)$ either had no college degree or the college information was missing in 
Table 1

College Background

\begin{tabular}{lrr}
\hline College Background & $N$ & $\%$ \\
\hline Degree Type & & \\
$\quad$ Four-year Bachelor's Degree & 2,964 & $74 \%$ \\
Two-Year Associate Degree & 359 & $9 \%$ \\
$\quad$ No Degree & 701 & $17 \%$ \\
Aviation Degree & & \\
$\quad$ Yes & 1,665 & $41 \%$ \\
No & 800 & $20 \%$ \\
Missing & 1,559 & $39 \%$ \\
AABI Flight Program & & \\
Yes & 759 & $19 \%$ \\
No & 1,706 & $42 \%$ \\
\hline
\end{tabular}

Note. $N=4024$.

their records. From the collected academic data, three college background variables were defined. Table 1 shows the three college background variables.

The first variable was Degree Type-a two-year Associate Degree or a four-year Bachelor's Degree. "No Degree" indicates that either the pilot did not have a college degree or there was no degree information in the pilot's record.

Based on the name of the college degree, Aviation Degree was defined as any college degree related to the aviation or aerospace industry. If a degree contained words such as aviation, flight, airport, aerospace, or other aviation terminology it was considered to be an aviation degree. Many aviation degrees were not flight degrees.

If a college or university was listed in AABI (2012), and the name of the college degree was listed as an "AABIaccredited flight program," then a pilot was counted as having a degree from an AABI Flight Program.

\section{Descriptive Statistics: Piloting Backgrounds}

The data collected included information about pilots' certificates, military background, advanced pilot training, flight instructor experience, total flight hours, and previous corporate or airline experience. Table 2 shows the six piloting background variables.

The Airline Safety and Federal Aviation Administration Extension Act of 2010 requires all airline pilots to have an ATP certificate; however, only $14 \%$ of the pilots in the dataset had an ATP certificate. Concerning military pilots, these data confirm a recent trend that very few regional airline pilots come from the military; therefore, the Military Pilot variable was not analyzed. Another background variable, Advanced Pilot Training, was collected to determine where the pilots earned their advanced pilot training (beyond the Private Pilot certificate).

Historically, flight instructing has been the bridge between finishing advanced pilot training and being hired as a pilot for an airline. The majority of the hired pilots were Certificated Flight Instructors (CFIs), and many accumulated
Table 2

Piloting Background

\begin{tabular}{lrr}
\hline Piloting Background & $\mathrm{N}$ & $\%$ \\
\hline Pilot Certificate & & \\
$\quad$ Airline Transport Pilot & 564 & $14 \%$ \\
$\quad$ Commercial & 3,460 & $86 \%$ \\
Military Pilot & & \\
$\quad$ Yes & 178 & $4 \%$ \\
No & 3,846 & $96 \%$ \\
Advanced Pilot Training Source & & \\
Military & 134 & $3 \%$ \\
College Flight Program & 2,087 & $52 \%$ \\
Part 141 or 142 Training Center & 898 & $22 \%$ \\
Part 61 & 905 & $23 \%$ \\
Certificated Flight Instructor & & \\
Yes & 3,485 & $87 \%$ \\
$\quad$ No & 539 & $13 \%$ \\
Dual Given $>$ 200 hours & & \\
Yes & 1,278 & $32 \%$ \\
No & 123 & $3 \%$ \\
Missing & 2,623 & $65 \%$ \\
Prior Experience & & \\
Airline & 1,484 & $37 \%$ \\
Corporate & 698 & $17 \%$ \\
None & & $46 \%$ \\
\hline
\end{tabular}

Note. $N=4024$.

over 200 hours as a flight instructor (Dual Given), which qualified them to train first-time flight instructor applicants (Certification: Pilots, Flight Instructors, and Ground Instructors, $2012 \S 61.195)$. Some pilots in this study had prior experience at other regional or major airlines; others had experience in corporate (or business) flying.

Based on current regulations, the most significant source variable was Total Flight Hours. Only 3,898 pilot records (97\%) reported Total Flight Hours, ranging from 216 hours to 22,000 hours $(\mathrm{M}=1,797, \mathrm{SD}=1,703)$. Considering that 1,500 Total Flight Hours was proposed as a requirement under the Airline Safety and Federal Aviation Administration Extension Act of 2010, Total Flight Hours were grouped into four categories, as shown in Figure 1.

\section{Descriptive Statistics: Outcome Variables}

There is great variability in training performance reports kept by the airlines. With no industry standard for record keeping, the combined training reports from seven airlines produced few integrative results. Table 3 shows the four outcome variables.

The outcome variable, Extra Training Events, was the number of repeated training events, regardless of type or reason, that a pilot needed to complete an airline's training program, up to Initial Operating Experience (IOE). Extra Training Events $(\mathrm{M}=0.35, \mathrm{SD}=1.52)$ ranged from 0 to 38. Another outcome variable, Training Completion, documented whether a pilot completed the training with the airline, including IOE. During a pilot's first year 


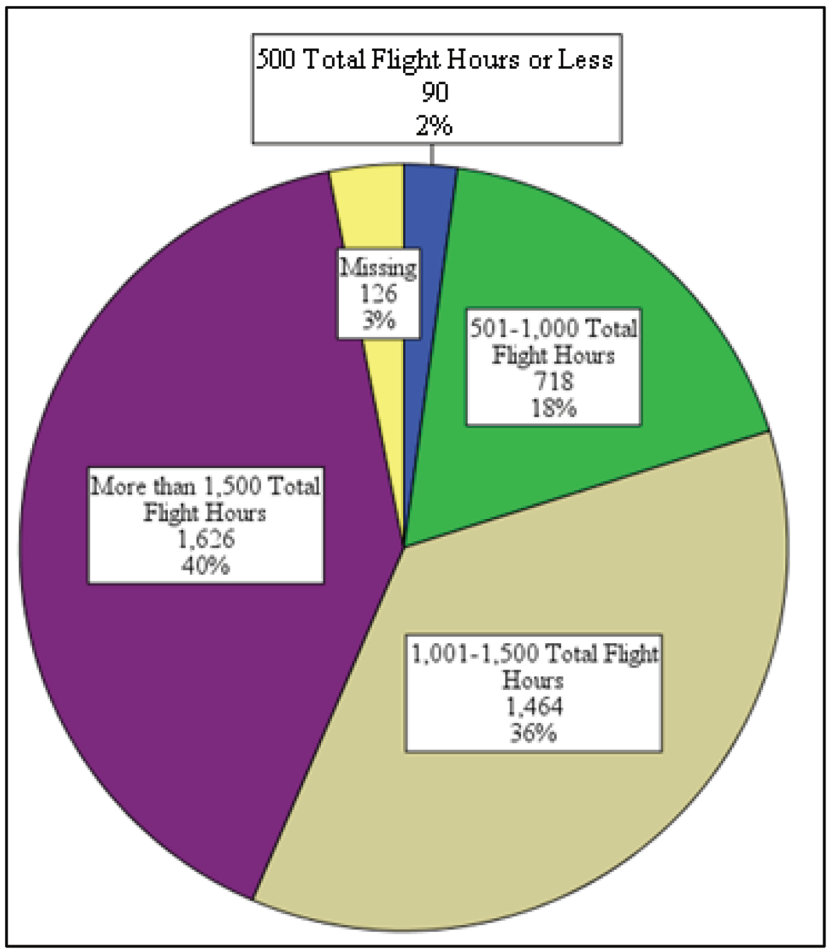

Figure 1. Description of the categorical variable, Groupings of Total Flight Hours.

(probationary year), the pilot may be observed by a check pilot to review piloting skills. These First Year Line Observations are not mandatory and are usually scored as satisfactory or unsatisfactory. Towards the end of their first year, pilots returned to the training center for recurrent training. In First Year Recurrent Training, pilots may receive one or more unsatisfactory scores which must be corrected before they return to line operations.

Table 3

Outcome Variables

\begin{tabular}{lrc}
\hline Outcome Variables & $\mathrm{N}$ & $\%$ \\
\hline Extra Training Events & & \\
$\quad$ Yes & 726 & $18 \%$ \\
No & 3,297 & $82 \%$ \\
$\quad$ Missing & 4 & $0.1 \%$ \\
Training Completion & 3,745 & $93 \%$ \\
$\quad$ Yes & 277 & $7 \%$ \\
No & 4 & $0.1 \%$ \\
Missing & & \\
Unsatisfactory First Year Line Observation & 50 & $1 \%$ \\
$\quad$ Yes & 3,744 & $94 \%$ \\
No & 200 & $5 \%$ \\
Missing & & \\
Unsatisfactory First Year Recurrent Training & 206 & $5 \%$ \\
$\quad$ Yes & 3,618 & $90 \%$ \\
No & 200 & $5 \%$ \\
Missing & & \\
\hline
\end{tabular}

Note. $N=4,024$.
Table 4

Comparison of Extra Training Events Based on College Degree

\begin{tabular}{|c|c|c|c|c|}
\hline $\begin{array}{l}\text { Extra Training } \\
\text { Events }\end{array}$ & & None & $\begin{array}{l}\text { Associate's } \\
\text { Degree }\end{array}$ & $\begin{array}{l}\text { Bachelor's } \\
\text { Degree }\end{array}$ \\
\hline Extra Training & $\begin{array}{l}\text { Observed/ } \\
\text { Expected }\end{array}$ & $156 / 126$ & $67 / 65$ & $500 / 532$ \\
\hline (YES) & Std. Residual & $2.7^{\mathrm{a}}$ & 0.3 & 1.4 \\
\hline Extra Training & $\begin{array}{l}\text { Observed/ } \\
\text { Expected }\end{array}$ & $545 / 575$ & $292 / 294$ & $2460 / 2428$ \\
\hline$(\mathrm{NO})$ & Std. Residual & 1.2 & 0.3 & 0.7 \\
\hline
\end{tabular}

\section{Outcome: Extra Training Events}

Chi-squares were calculated to test whether there was a difference in Extra Training Events based on college background and piloting background. For Extra Training Events, the non-significant background variables were:

- AABI Flight Program: $\chi^{2}(1, N=2462)=2.71, p=$ .100

- Pilot Certificate: $\chi^{2}(1, N=4020)=0.88, p=.348$

- CFI: $\chi^{2}(1, N=4020)=0.11, p=.739$

For Extra Training Events, the significant background variables were:

- College Degree: See Table 4

- Aviation Degree: See Table 5

- Advanced Pilot Training: See Table 6

- Prior Experience: See Table 7

- Total Flight Hours: See Table 8

\section{Outcome: Training Completion}

Chi-squares were calculated to test whether there was a difference in Training Completion based on college background and piloting background. For Training Completion, the non-significant background variables were:

- College Degree: $\chi^{2}(2, N=4022)=4.05, p=.132$

- Prior Experience: $\chi^{2}(2, N=4022)=5.77, p=.056$

For Training Completion, the significant background variables were:

Table 5

Comparison of Extra Training Events Based on Aviation Degree

\begin{tabular}{llll}
\hline $\begin{array}{l}\text { Extra Training } \\
\text { Events }\end{array}$ & & $\begin{array}{c}\text { Aviation } \\
\text { Degree (YES) }\end{array}$ & $\begin{array}{c}\text { Aviation } \\
\text { Degree (NO) }\end{array}$ \\
\hline Extra Training & Observed/Expected & $213 / 235$ & $135 / 113$ \\
(YES) & Std. Residual & 1.4 & $2.1^{\mathrm{a}}$ \\
Extra Training & Observed/Expected & $1450 / 1427$ & $664 / 686$ \\
(NO) & Std. Residual & 0.6 & 0.8 \\
\hline
\end{tabular}

$\chi^{2}(1, N=2462)=7.43 ; p=.006$. Phi $=.055$. ${ }^{\text {a } P i l o t s ~ w i t h ~ n o ~ A v i a t i o n ~}$ Degree had more Extra Training Events than expected. 
Table 6

Comparison of Extra Training Events Based on Advanced Pilot Training

\begin{tabular}{llllcc}
\hline Extra Training Events & & College & Military & Non-college (Part 141 or 142) & Non-college (Part 61) \\
\hline Extra Training (YES) & Observed/Expected & $315 / 375$ & $27 / 24$ & $178 / 162$ & $203 / 163$ \\
& Std. Residual & $3.1^{\mathrm{a}}$ & 0.6 & 1.3 & $3.2^{\mathrm{b}}$ \\
Extra Training (NO) & Observed/Expected & $1769 / 1709$ & $106 / 109$ & $720 / 737$ & $702 / 742$ \\
& Std. Residual & 1.4 & .3 & 0.6 & 1.5 \\
\hline
\end{tabular}

$\chi^{2}(3, N=4020)=26.30 ; p<.001$. Cramer's V $=.081$. ${ }^{\text {a }}$ Pilots who received Advanced Pilot Training in college had fewer Extra Training Events than expected. ${ }^{\mathrm{b}}$ Pilots who received Advanced Pilot Training in non-college (Part 61) had more Extra Training Events than expected.

Table 7

Comparison of Extra Training Events Based on Prior Experience

\begin{tabular}{|c|c|c|c|c|}
\hline Extra Training Events & & None & Airline & Corporate \\
\hline Extra Training & Observed/Expected & $371 / 331$ & $187 / 266$ & $165 / 126$ \\
\hline (YES) & Std. Residual & $2.2^{\mathrm{a}}$ & $4.9^{\mathrm{b}}$ & $3.5^{\mathrm{c}}$ \\
\hline Extra Training & Observed/Expected & $1470 / 1509$ & $1294 / 1215$ & $533 / 573$ \\
\hline$(\mathrm{NO})$ & Std. Residual & 1.0 & $2.3^{\mathrm{b}}$ & 1.6 \\
\hline
\end{tabular}

$\chi^{2}(2, N=4020)=49.82 ; p<.001$. Cramer's V $=111$. ${ }^{\text {a} P i l o t s ~ w i t h ~ n o ~ P r i o r ~ E x p e r i e n c e ~ h a d ~ m o r e ~ E x t r a ~ T r a i n i n g ~ E v e n t s ~ t h a n ~ e x p e c t e d . ~}{ }^{\mathrm{b}}$ Pilots with Prior Airline Experience had fewer Extra Training Events than expected. 'Pilots with Prior Corporate Experience had more Extra Training Events than expected.

Table 8

Comparison of Extra Training Events Based on Total Flight Hours

\begin{tabular}{llllll}
\hline Extra Training Events & & $0-500$ & $501-1000$ & $1001-1500$ & $>1500$ \\
\hline Extra Training & Observed/Expected & $20 / 16$ & $150 / 126$ & $246 / 257$ & $267 / 285$ \\
(YES) & Std. Residual & 1.1 & $2.1^{\mathrm{a}}$ & 0.7 & 1.1 \\
Extra Training & Observed/Expected & $70 / 74$ & $568 / 592$ & $1217 / 1207$ & $1357 / 1339$ \\
(NO) & Std. Residual & 0.5 & 1.0 & 0.3 & 0.5 \\
\hline
\end{tabular}

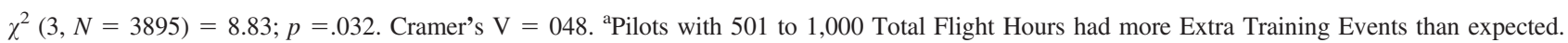

- Aviation Degree: See Table 9

- AABI Flight Program: See Table 10

- Pilot Certificate: See Table 11

- CFI: See Table 12

- Advanced Pilot Training: See Table 13

- Total Flight Hours: See Table 14
Outcome: Unsatisfactory in First Year Line Observation

Chi-squares were calculated to test whether there was a difference in Unsatisfactory in First Year Line Observation based on college background and piloting background. For Unsatisfactory in First Year Line Observation, the nonsignificant background variables were:

Table 9

Comparison of Completions Based on Aviation Degree

\begin{tabular}{llll}
\hline Completions & & Aviation Degree (YES) & Aviation Degree (NO) \\
\hline Completions & Observed/Expected & $1565 / 1537$ & $709 / 737$ \\
(YES) & Std. Residual & 0.7 & 1.0 \\
Completions & Observed/Expected & $100 / 128$ & $90 / 62$ \\
(NO) & Std. Residual & $2.5^{\mathrm{a}}$ & $3.6^{\mathrm{b}}$ \\
\hline
\end{tabular}

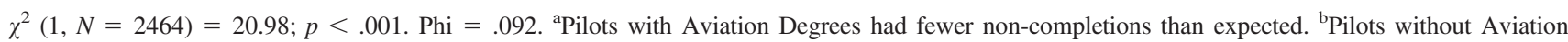
Degrees had more non-completions than expected.

Table 10

Comparison of Completions Based on AABI Flight Program

\begin{tabular}{llcc}
\hline Completions & & AABI Flight Degree (YES) & AABI Flight Degree (NO) \\
\hline Completions & Observed/Expected & $720 / 700$ & $1554 / 1573$ \\
(YES) & Std. Residual & 0.7 & 0.5 \\
Completions & Observed/Expected & $39 / 59$ & $151 / 132$ \\
(NO) & Std. Residual & $2.6^{\mathrm{a}}$ & 1.7 \\
\hline
\end{tabular}

$\chi^{2}(1, N=2464)=10.20 ; p=.001, \mathrm{Phi}=.064 .{ }^{\mathrm{a}}$ Pilots from AABI Flight Programs had fewer non-completions than expected. 
Table 11

Comparison of Completions Based on Pilot Certificate

\begin{tabular}{llll}
\hline Completions & & ATP & Commercial \\
\hline Completions & Observed/Expected & $492 / 523$ & $3253 / 3221$ \\
(YES) & Std. Residual & 1.4 & 0.6 \\
Completions & Observed/Expected & $70 / 39$ & $207 / 238$ \\
(NO) & Std. Residual & $5.0^{\mathrm{a}}$ & $2.0^{\mathrm{b}}$ \\
\hline
\end{tabular}

$\chi 2(1, N=4022)=31.59 ; \mathrm{p}<.001$. Phi $=.089 .{ }^{\mathrm{a}}$ Pilots with an ATP certificate had more non-completions than expected. ${ }^{b}$ Pilots with a commercial certificate had fewer non-completions than expected.
Table 12

Comparison of Completions Based on Instructor Certificate

\begin{tabular}{llll}
\hline Completions & & CFI (Yes) & CFI (No) \\
\hline Completions & Observed/Expected & $3265 / 3244$ & $480 / 501$ \\
(YES) & Std. Residual & 0.4 & 0.9 \\
Completions & Observed/Expected & $219 / 240$ & $58 / 37$ \\
(NO) & Std. Residual & 1.4 & $3.4^{\mathrm{a}}$ \\
\hline
\end{tabular}

$\chi^{2}(1, N=4022)=14.68 ; p<.001$. Phi $=.060$. ${ }^{\text {a }}$ Pilots who did not have a CFI certificate had more non-completions than expected.

Table 13

Comparison of Completions Based on Advanced Training

\begin{tabular}{|c|c|c|c|c|c|}
\hline \multicolumn{2}{|l|}{ Completions } & \multirow{2}{*}{$\begin{array}{c}\text { College } \\
1989 / 1942\end{array}$} & \multirow{2}{*}{$\begin{array}{l}\text { Military } \\
116 / 124\end{array}$} & \multirow{2}{*}{$\begin{array}{c}\begin{array}{c}\text { Non-college } \\
\text { (Part 141 or 142) }\end{array} \\
841 / 836\end{array}$} & \multirow{2}{*}{$\begin{array}{c}\text { Non-college (Part 61) } \\
799 / 843\end{array}$} \\
\hline Completions & Observed/Expected & & & & \\
\hline (YES) & Std. Residual & 1.1 & .7 & 0.2 & 1.5 \\
\hline Completions & Observed/Expected & $97 / 144$ & $17 / 9$ & $57 / 62$ & $106 / 62$ \\
\hline (NO) & Std. Residual & $3.9^{\mathrm{a}}$ & $2.6^{\mathrm{b}}$ & 0.6 & $5.5^{\mathrm{c}}$ \\
\hline
\end{tabular}

$\chi^{2}(3, N=4022)=56.76 ; p<.001$. Cramer's V $=.119$. ${ }^{\text {a } P i l o t s ~ w h o ~ r e c e i v e d ~ A d v a n c e d ~ P i l o t ~ T r a i n i n g ~ i n ~ c o l l e g e ~ h a d ~ f e w e r ~ n o n-c o m p l e t i o n s ~ t h a n ~}$ expected. ${ }^{b}$ Pilots who received Advanced Pilot Training in the military had more non-completions than expected. ${ }^{\mathrm{c}}$ Pilots who received Advanced Pilot Training in non-college (Part 61) had more non-completions than expected.

Table 14

Comparison of Completions Based on Total Flight Hours

\begin{tabular}{lllll}
\hline Completions & & $0-500$ & $501-1000$ & $1001-1500$ \\
\hline Completions & Observed/Expected & $87 / 84$ & $673 / 667$ & $1376 / 1360$ \\
(YES) & Std. Residual & 0.4 & 0.2 & 0.4 \\
Completions & Observed/Expected & $3 / 6$ & $45 / 51$ & $88 / 104$ \\
(NO) & Std. Residual & 1.3 & 0.8 & 1.5 \\
\hline
\end{tabular}

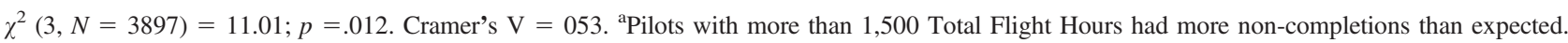

- College Degree: $\chi^{2}(2, N=3824)=1.11, p=574$

- Aviation Degree: $\chi^{2}(1, N=2323)=1.89, p=169$

- AABI Flight Program: $\chi^{2}(1, N=2323)=3.34, p=$ .068

- Prior Experience: $\chi^{2}(2, N=3824)=8771, p=.647$

- Pilot Certificate: $\chi^{2}(1, N=3824)=1.22, p=.270$

- CFI: $\chi^{2}(14, N=3824)=1.19, p=.276$

- Advanced Pilot Training: $\chi^{2}(3, N=3824)=1.48, p$ $=.688$

- Total Flight Hours: $\chi^{2}(3, N=3700)=.902, p=.825$

For Unsatisfactory in First Year Line Observation, there were no significant variables.

\section{Outcome: Unsatisfactory in First Year Recurrent Training}

Chi-Squares were calculated to test whether there was a difference in Unsatisfactory in First Year Recurrent Training based on college background and piloting background. For Unsatisfactory in First Year Recurrent Training, the nonsignificant background variables were:

- College Degree: $\chi^{2}(2, N=3824)=.541, p=.763$

- Aviation Degree: $\chi^{2}(1, N=2323)=.312, p=.576$
- AABI Flight Program: $\chi^{2}(1, N=2323=.546, p=$ .460

- Pilot Certificate: $\chi^{2}(1, N=3824)=489, p=.484$

- Advanced Pilot Training: $\chi^{2}(3, N=3824)=2.37, p$ $=.499$

For Unsatisfactory in First Year Recurrent Training, the significant background variables were:

- Prior Experience: See Table 15

- CFI: See Table 16

- Total Flight Hours: See Table 17

\section{Discussion}

Comparison Between the 2010 Pilot Source Study and the 2012 Pilot Source Study

The primary purpose of this research was to expand the scope of the 2010 Pilot Source Study (Smith et al., 2010) and to validate the results. The 2012 Pilot Source Study utilized the same methodology; however, it included data from seven new regional airlines producing a single 
Table 15

Comparison of First Year Recurrent Training Based on Prior Experience

\begin{tabular}{|c|c|c|c|c|}
\hline \multicolumn{2}{|l|}{ Recurrent Training } & \multirow{2}{*}{$\begin{array}{c}\text { None } \\
1650 / 1635\end{array}$} & \multirow{2}{*}{$\begin{array}{c}\text { Airline } \\
1322 / 1341\end{array}$} & \multirow{2}{*}{$\begin{array}{c}\text { Corporate } \\
646 / 642\end{array}$} \\
\hline Unsatisfactory & Observed/Expected & & & \\
\hline (No) & Std. Residual & 0.4 & 0.5 & 0.1 \\
\hline Unsatisfactory & Observed/Expected & $78 / 93$ & $95 / 76$ & $33 / 37$ \\
\hline (Yes) & Std. Residual & 1.6 & $2.1^{\mathrm{a}}$ & 0.6 \\
\hline
\end{tabular}

$\chi^{2}(2, N=3824)=7.78 ; p=.020$. Cramer's $\mathrm{V}=045 .{ }^{\mathrm{a}}$ Pilots who had previous airline experience had more unsatisfactory remarks in First Year Recurrent Training than expected.

Table 16

Comparison of First Year Recurrent Training Based on Instructor Certificate

\begin{tabular}{llll}
\hline Recurrent Training & & CFI (Yes) & CFI (No) \\
\hline Unsatisfactory & Observed/Expected & $3165 / 3141$ & $453 / 477$ \\
(No) & Std. Residual & 0.4 & 1.1 \\
Unsatisfactory & Observed/Expected & $155 / 179$ & $51 / 27$ \\
(Yes) & Std. Residual & 1.8 & $4.6^{\mathrm{a}}$ \\
\hline
\end{tabular}

Table 17

Comparison of First Year Recurrent Training Based on Total Flight Hours

\begin{tabular}{llllll}
\hline Recurrent Training & & $0-500$ & $501-1000$ & $1001-1500$ & $>1500$ \\
\hline Unsatisfactory & Observed/Expected & $85 / 85$ & $629 / 652$ & $1337 / 1317$ & $1444 / 1442$ \\
(No) & Std. Residual & 0.0 & 0.9 & 0.6 & 0.1 \\
Unsatisfactory & Observed/Expected & $5 / 5$ & $61 / 38$ & $57 / 77$ & $82 / 85$ \\
(Yes) & Std. Residual & 0.0 & $3.7 \mathrm{a}$ & $2.3 \mathrm{~b}$ & 0.3
\end{tabular}

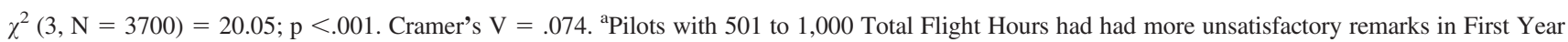
Recurrent Training than expected. ${ }^{\text {b} P i l o t s ~ w i t h ~ 1,001 ~ t o ~ 1,500 ~ T o t a l ~ F l i g h t ~ H o u r s ~ h a d ~ h a d ~ f e w e r ~ u n s a t i s f a c t o r y ~ r e m a r k s ~ i n ~ F i r s t ~ Y e a r ~ R e c u r r e n t ~ T r a i n i n g ~}$ than expected.

dataset. Table 18 is a comparison of the results between the two studies.

The results are consistent for many variables, indicating an ability to generalize to the larger regional airline population. The first three independent variables analyzed are in regards to the subjects' college background and the comparison to how each individual performed during initial training at the regional airline. The only significant finding in regards to simply having a four-year degree, two-year degree or no degree was found in analyzing the need for

Table 18

Comparison Between the 2010 Pilot Source Study and the 2012 Pilot Source Study

\begin{tabular}{|c|c|c|}
\hline Pilot Source Variable & 2010 Pilot Source Study SIGNIFICANT Results & 2012 Pilot Source Study SIGNIFICANT Results \\
\hline \multirow[t]{2}{*}{ College Degree } & Not Significant & Fewer Extra Training Events \\
\hline & Not Significant & Not Significant \\
\hline \multirow[t]{2}{*}{ Aviation Degree } & Fewer Extra Training Events & Fewer Extra Training Events \\
\hline & More Completions & More Completions \\
\hline \multirow[t]{2}{*}{ AABI Flight Program } & Fewer Extra Training Events & Not Significant \\
\hline & More Completions & More Completions \\
\hline \multirow[t]{3}{*}{ Source of Advanced Pilot Training } & College: Fewer Extra Training Events & College: Fewer Extra Training Events \\
\hline & College: More Completions & College: More Completions \\
\hline & & Non-College, Part 61: Fewer Completions \\
\hline \multirow[t]{2}{*}{ Pilot Certificates } & N/A (not collected) & Not Significant \\
\hline & N/A (not collected) & Commercial: More Completions than ATP \\
\hline \multirow[t]{2}{*}{ Total Flight Hours } & 501-1,000 Hours: Fewer Extra Training Events & 501-1,000 Hours: More Extra Training Events \\
\hline & 501-1,000 Hours: More Completions & 1,001-1,500 Hours: More Completions \\
\hline \multirow[t]{2}{*}{ Flight Instructor } & Fewer Extra Training Events & Not Significant \\
\hline & More Completions & More Completions \\
\hline \multirow[t]{2}{*}{ Previous Experience } & Not Significant & Airline: Fewer Extra Training Events \\
\hline & Not Significant & Not Significant \\
\hline
\end{tabular}


extra training events. Individuals with no college degree had more extra training events than expected, while individuals with a four-year degree had fewer extra training events than expected. There was evidence that supported the importance of a specialized degree in an aviationrelated field of study. In both studies it remains consistent that individuals are more successful in regional airline training when they obtain an aviation-related degree, in addition to a degree from an AABI-accredited flight program. Only $19 \%$ of the 4,024 pilots included in the 2012 Pilot Source Study graduated from AABI-accredited flight programs. As of 2012, the nation faces a looming pilot shortage in the coming years (Boeing, 2012). The pipeline of pilot applicants entering the industry from AABI-accredited flight programs will not be sufficient to meet the demand.

On August 1, 2013, section 216 of the Airline Safety and Federal Aviation Administration Extension Act of 2010 will enforce that all flight crewmembers operating in Part 121 air carriers must hold an FAA-issued ATP certificate. The results of the current research indicate that commercial pilots were more successful in completing training than those holding an ATP certificate. This would indicate that quality of experience, not just quantity of hours and certification criteria, better predicts pilot performance at the regional carriers. Also note that only $14 \%$ of the 4,024 pilots in the study actually held an ATP certificate at the time of hire with the regional carrier. This exemplifies a disconnect between the recently passed legislation and current industry hiring practices at regional air carriers.

The aeronautical experience requirements for the ATP certificate are set forth in Certification: Pilots, Flight Instructors, and Ground Instructors (2012). Specifically, 14 C.F.R.§ 61.159 stipulates "1,500 total flight hours, including at least 500 hours of cross- country flight time, 100 hours of night flight time, and 75 hours of instrument flight time." According to the results of both the 2010 Pilot Source Study and the 2012 Pilot Source Study, pilots with more than 1,500 hours were not as successful in regional airline training as some pilot groupings with fewer than 1,500 hours. This indicates that using a quantity measure of Total Flight Hours as the predictor of success is not suitable for the aviation industry that constantly strives to improve safety and training performance. Rather than relying solely on a quantitative measure of total flight hours, the industry should also consider two qualitative measures: (a) the quality of training a pilot receives, and (b) the quality of flight hours a pilot obtains after training is complete.

A common career path for an aspiring airline pilot often includes time spent as a CFI. Of the 4,024 pilots included in the PSS Phase III, $87 \%$ of them held a CFI certificate, indicating that the majority of civilian pilots gain experience in this activity. Pilots who held a CFI certificate performed better in regional airline training than those who were not CFIs. These results are consistent in both the 2010 Pilot Source Study and the 2012 Pilot Source Study.

The similar results between the two phases of the Pilot Source Study, each containing completely separate data sets, indicate that most of the predictor variables used in the research can be generalized to the regional airline industry as a whole. The notable difference between the two sets of data exists within the Total Flight Hour variable. The current study, 2012 Pilot Source Study, found that pilots with 1,001 to 1,500 hours performed better in initial training; whereas in the 2010 Pilot Source Study, pilots with 501-1,000 hours performed better. In fact, in the 2012 Pilot Source Study, the same grouping of pilots with 501-1,000 total flight hours had more extra training events than expected.

It should be noted that the 2012 Pilot Source Study included data from pilots hired between 2010 and 2011, whereas the 2010 Pilot Source Study did not include those years. Pilot hiring that took place between 2010 and 2011 at the regional airlines happened after a long period of virtually no hiring due to economic and industry conditions between 2008 and 2009. Pilots who endeavored to be hired by a regional airline had to wait longer, thus accruing more total flight hours as a CFI prior to commencing training at the air carrier. Overall, the evidence in both phases of the Pilot Source Study indicates that flight hours are not a good predictor of performance.

\section{Recommendations for Further Research}

The 2010 Pilot Source Study and the 2012 Pilot Source Study both relied heavily on single variable analysis in relation to the outcome variables. Future research should focus on multivariate analysis of the combined large dataset in order to provide a more in-depth understanding of the complexity related to the pilot supply and subsequent success at training in a regional airline. Regression analysis, predictive modeling, and path analysis are a few examples of multivariate analysis that could be used to analyze these data.

With the signing of the Airline Safety and Federal Aviation Administration Extension Act of 2010 (PL 111216), many areas of related research need to be studied. The 2012 Pilot Source Study found that successful pilot applicants came from AABI-accredited flight programs; however, the number of these pilots made up only a small percentage of the sample. Research into the supply of pilots from AABI-accredited flight programs is needed to understand this pipeline. Additionally, research that can provide a better understanding of the career aspirations of the student population is important. Collegiate programs may graduate a large number of pilots annually, but only a percentage of them desire to fly for regional airlines.

Further research must also be conducted regarding current and future hiring practices at regional airlines. The impact of the Airline Safety and Federal Aviation Administration Extension Act of 2010 (PL 111-216) on 
regional airlines is substantial. The question remains-how will the regional airlines find and recruit pilots who meet the requirements detailed in the law? Research must also examine the likely possibility of a depleted pilot pool and its impact on regional airline hiring and operations.

\section{Conclusion}

The results found in both the 2010 Pilot Source Study and the 2012 Pilot Source Study are important for pilots and for the airlines who wish to hire them. This is the first large-scale research initiative to combine data from multiple regional airlines to better understand the complexities of success for pilot candidates. It is recognized that, unlike other professional fields such as medicine and law, there are many ways in which a person can train and prepare to be a professional pilot. However, this research shows that, when pilots dedicate four years to a college education in the field of aviation, they perform better in pilot training at a regional airline.

\section{References}

Air Line Pilots Association, International. (2009). Producing a professional airline pilot: Candidate screening, hiring, training, and mentoring (ALPA White Paper). Washington, DC: Air Line Pilots Association, International. Retrieved from http:/www.alpa.org/portals/ alpa/pressroom/inthecockpit/ProducingProfessionalPilot_9-2009.pdf

Airline Safety and Federal Aviation Administration Extension Act of 2010. Pub.L. 111-216,124 Stat, 2348. (2010).

Boeing. (2012). Long term market: Current market outlook 2012-2031. Retrieved from http://www.boeing.com/commercial/cmo/index.html

Certification: Pilots, Flight Instructors, and Ground Instructors, 14 C.F.R. $\S 61$, (2012).
Federal Aviation Administration. (2010). Answering the call to action on airline safety and pilot training (FAA-HQ-101038). Washington, DC: Department of Transportation.

Fanjoy, R. O., Young, J. P., \& Suckow, M. W. (2006). The experience factor: A regional airline view of pilot candidate qualifications. Collegiate Aviation Review, 24 (1), 67-72.

Federal Aviation Administration. (2010, February 8). New pilot certification requirements for air carrier operations (ANPRM, Docket No. FAA-2010-0100; Notice No. 10-02). Washington, DC: Department of Transportation.

Fullingim, J. F. (2007). Regional airline qualifications: A study in the marketability of higher education graduates (Doctoral dissertation, University of North Texas). Retrieved from http://digital.library.unt. edu/ark:/67531/metadc5181/m1/1/high_res_d/dissertation.pdf

Lopez, R. (2010). FAA cites progress in regional airline safety. Aviation Today's Daily Brief, 2 (22), 2-24.

National Transportation Safety Board. (2007a). Aircraft accident report: Crash of Pinnacle Airlines Flight 3701 Bombardier CL-600-2B19, N8396A Jefferson City, Missouri October 14, 2004 (NTSB/AAR-07/ 01). Washington, DC: National Transportation Safety Board.

National Transportation Safety Board. (2007b). Aircraft accident report: Attempted takeoff from wrong runway Comair Flight 519 Bombardier CL-600-2B19, N431CA Lexington, Kentucky August 27, 2006 (NTSB/ AAR-07/05). Washington, DC: National Transportation Safety Board.

National Transportation Safety Board. (2010). Aircraft accident report: Loss of control on approach Colgan Air, Inc. Operating as Continental Connection Flight 3407 Bombardier DHC-8-400, N200WQ Clarence Center, New York February 12, 2009 (NTSB/AAR-10/01). Washington, DC: National Transportation Safety Board.

Regional Airline Association. (2012). U.S. regional airline fact sheet. Retrieved from www.raa.org/Portals/0/IndustryStats/usRegional FactSheetMay2011.pdf

Smith, G. M. (2011). Consultant agreement. Unpublished manuscript, Embry-Riddle Aeronautical University, Daytona Beach, FL.

Smith, G. M., Bjerke, E., NewMyer, D. A., Niemczyk, M., \& Hamilton, R. A. (2010). Pilot source study: An analysis of pilot backgrounds and subsequent successin U.S. regional airline training programs, International Journal of Applied Aviation Studies, 10 (1), 73-96.

SurveyMonkey. (2012). Web-based surveys. Retrieved from http://www. surveymonkey.com/ 